\title{
The Whole Grade Acceleration Policy in the Kingdom of Saudi Arabia and the State of Massachusetts, USA-An Analytical Comparative Study
}

\author{
Abdulhamid Alarfaj ${ }^{1}$ \& Reem Abdul Latif Al-Omair ${ }^{2}$ \\ ${ }^{1}$ Special Education Department, Education School, King Faisal University, Saudi Arabia \\ ${ }^{2}$ Faculty of Education, King Faisal University, Saudi Arabia \\ Correspondence: Abdulhamid Alarfaj, Special Education Department, Education School, King Faisal University, \\ Saudi Arabia.
}

Received: February 9, 2020

Accepted: March 14, 2020

Online Published: July 23, 2020

doi:10.5539/ies.v13n8p55

URL: https://doi.org/10.5539/ies.v13n8p55

\begin{abstract}
The research aims, through a comparative analytical study, to unveil whether there is an actual whole-grade acceleration policy in the kingdom of Saudi Arabia (KSA) if compared with that applied at Massachusetts, USA. Adopting such a policy secures the right of the gifted student to grow academically in proportion with his peculiar potentials. The research adopts the comparative analytical method (qualitative) using two tools: document analysis and semi-structured interview. The sample of the study comprised two education supervisors in charge of acceleration system in the department of the gifted in KSA and school principals applying the system in the state of Massachusetts. The foremost result, which the study came up to, was that the Saudi educational system has a comprehensive written acceleration policy based on scientific frameworks, while Massachusetts doesn't have a specific document for applying a comprehensive acceleration policy. The research concluded with some recommendations among which are: The comprehensive acceleration policy in KSA still needs to develop, especially in the following areas: Classes and study levels on which the acceleration system and guidance services are applied, and The need to review acceleration procedures as they are among the obstacles that hinder an active application of the policy at the present time.
\end{abstract}

Keywords: whole-grade acceleration, acceleration policy, document of acceleration policy, gifted student

\section{Introduction}

Interest in the students who are academically and mentally gifted and outstanding is one of the major educational issues of today that could help in investing the potentials of such students who are pivotal in the development and prosperity of the society. As those students have special academic, cognitive, social, and psychological needs peculiar to them, they in return are in need for educational services different from those that are being offered with respect to ordinary educational school programs.

Despite the intensive efforts exerted by scholars and educators to design and develop special services of the gifted, yet these can be substituted by two basic alternatives: education enrichness and academic acceleration. Acceleration method is one of those academic services through which cognitive content, that suits the gifted and reinforces his capabilities, are offered. It is considered one of the methods that has been educationally controversial; it resulted from the gap between what researches and studies had come up to, regarding the significance and benefits of acceleration, and the mistaken concepts that many guardians and educators hold with reference to negative impact entailing from academic acceleration, specifically the psychological and social aspects of the students who experienced acceleration.

The essential objective of academic acceleration is manifested in meeting the increasing academic needs of the gifted students to cope with their mental, not chronological age. Thus, one can say that such an objective is one of the pillars upon which caring for the gifted rests and by which their needs can be satisfied and their mental capabilities be invested to the greatest possibility. Al-Jugheiman (2018) assured that the objective of the acceleration process was not only student's educational acceleration, but also necessitated that educators take into consideration to establishing an equilibrium between mental and psychological readiness of the student and the level to which he is intended to reach. Consequently, achieving positive and active results of acceleration 
depends on two fundamental factors:

First, Student's academic readiness that is a basic justified factor for the process of acceleration.

Second, availability of an educational policy that allows moving forward on the ladder of education by which the gifted student progresses in the educational program earlier than his peers. Student's academic readiness is measured by the level of mental ability he has. This can be determined through the disclosure and identification policy set by education management of the state, which supposedly should be clearly stipulated upon indefinite steps.

\subsection{Problem of the Study}

Since the start of $20^{\text {th }}$ century, efforts of numerous educators were orchestrated toward conducting researches and studies on acceleration aiming to examine its effectivity and influence on developing the academic, psychological, and social capabilities of the gifted. That ended up with evidences on the positive relation of acceleration on all sides of the gifted student (Rogers, 2005). Despite that, acceleration remained the academic option that was not properly invested to the best. That might be traced back to the absence an educational document of an acceleration policy that is based on scientific framework propitious with the student's case and needs (Scott et al., 2017). Thus, the absence of such policy create confusion, for practitioners in applying the system in the field of education rejecting the system as that was easier for them than being forced to deal with any student in a way different from that of his peers (Scott et al., 2017).

\subsection{Questions of the Study}

Problem of the study is determined through answering the following major question:

To what extent does a policy based on academic frameworks relevant to whole-grade acceleration exist in Saudi Arabia and the state of Massachusetts in the U.S?

Answering this major question can be obtained through answers of the following sub-questions:

1) To what extent is, the whole grade acceleration system applied at academic levels?

2) To what extent do whole-grade acceleration procedures help achieve education objectives of sponsoring the gifted?

3) To what extent do special guidance services of whole grade acceleration system exist?

\subsection{Significance of the Study}

The significance of this study lies in the following:

- It lays down a clear whole-grade acceleration policy that helps the gifted student to develop in the educational program in accordance with his progress.

- It responds to the last report issued by the National Association for the gifted children (American Educational Research Association, 1999) regarding the development of whole-grade acceleration policy that agrees with the results the scientific studies of academic acceleration came up to.

- It responds to the recommendation of Sheppard's (2018) study that emphasized the need of educational field for more scientific studies related to educational bodies which believe in acceleration policy to secure opportunities and propitious academic experiences that help develop the gifted student, personally and cognitively.

- It copes with the 2030 vision of the Kingdom that emphasizes intensifying educational efforts to build up human minds in order to invest them in security development.

\subsection{Objectives of the Study}

- To verify whether there is a policy based on a clear scientific framework for whole-grade acceleration extant in both Saudi Arabia and the State of Massachusetts in the U.S.

- To comparatively analyze the range to which applying whole - grade acceleration was effective in both Saudi Arabia and Massachusetts.

- To unveil glitches and shortages, if available, in the current whole-grade acceleration with the intention of opening larger horizons for future studies in an attempt to solve such problems and to fill the gaps by providing a number of recommendations to improve acceleration.

\subsection{Limitations of the Study}

Limitations of the objectives: 
The study presents an analytical comparison between the whole grade acceleration policy of the gifted in Saudi Arabia and Massachusetts in the U.S.

Time and place limitations:

Second semester 1440/1441 A.H at schools of the gifted in Massachusetts and the gifted administration department at education offices in Saudi Arabia.

\subsection{Terminology of the Study}

1) Acceleration:

Procedurally, the researcher defines it as a procedure that modifies the educational hierarchical system to allow the gifted student to proceed in the study program faster than what is offered now. This procedure shortens the study period that the ordinary student needs

2) Whole-grade acceleration:

Procedure wise, the researcher defines it as the system that enables the gifted student to move up on the ladder of education that copes with his mental age. Thus, the student moves up to the next level whenever he realizes the conditions needed for promotion to a higher class.

3) Acceleration policy:

Procedure wise, it is identified as the official document which includes detailed procedures followed in applying the acceleration system. It represents the means followed by those in charge of the system throughout its application to the gifted students who deserve it.

4) Gifted student:

Procedurally, the researchers defines him to be the student who obtained a high score of intelligence (120) and above in any of the standardized scales and excelled in fields other than the cognitive, personal, and creative. Such super capabilities, in order to grow and develop, need a special care which the ordinary school programs don't offer.

\section{Literature Review}

\subsection{Talent Concept}

Throughout history of development of education, the concept of talent was given different names. Among the foremost of those were: giftedness, talent, creativity, excellence, and intelligence.

Researchers were unclear and confused about choosing a term which refers to an unusual performance in a specific field. Jarwan (2012) indicated that overlapping over terminologies on talent might be referred back to several reasons among which are the following: the issue of different translations for the term, ambiguity of meaning, in foreign dictionaries, direct transfer of foreign theories in the fields of talent excellence, as they are rare in Arabic theories.

The first theories of talent were linked to the concept of intelligence. The dominating belief was that talent implied the rate of inherited heretic intelligence as Galton (1869) indicated. Determining talent was conducted through intelligent tests which measured the level of individual's mental achievement. It was the foundation on which Binet's tests were based, followed by Terman and Oden (1947) who adopted the one-factor theory and intelligence rate as indicators of the talent. Development of the talent concept theory had contributed to the daring changes that affected modern scientific researchers with regard to meaning of the term talent that is manifested in defining the core of the talent, for depending on one factor can't determine the complex meaning of the term "talent" (Al-Jugheiman et al., 2009). Talent is not just a mental readiness which can be determined through intelligence measures and academic achievement, but determined by a variety of abilities in essence and indications and at Variance in the methods of measurements and excellence (Al-Jugheiman, 2018).

The gene factor (intelligence) is not the only element in creating talent, but in itself it can't come up without roots that reflect distinction and excellence. As a result, the modern approach to talent emphasizes the role of environment, being an essential factor in the growth and development of talent. Based on such modern trends regarding talent and excellence, a dire need for educational programs which serve people with high mental abilities, emerged. Such programs should help to develop and satisfy their psychological, social, and mental talents. Therefore, special programs for the talented students were designed to help them best utilize their potentials in an environment characterized by flexibility and challenge. Though such programs vary in form, yet most of them are alike, with regard to the goals they aspire to achieve. In general, all such programs might be included in three major ones: enrichment, acceleration, and guidance. 


\subsection{The Concept of Academic Acceleration and Its Types}

Acceleration and momentum are terms used to refer to the same meaning. The English term incorporates (Al-Baalabaki, 2003). The term in the literature concerned with educating the talented student means allowing the student to proceed in curriculum faster than his peers whether the acceleration was partial or total (Davis \& Rimm, 1989). The definition that Al-Jugheiman (2018) adopted sounds to be more comprehensive as it describes academic acceleration to be "the move through the traditional curriculum in faster rates than the stereotyped one. In other words, it is modifying the curriculum or the study ladder in order to meet students' readiness and needs. With reference to the previous concept, we can conclude that such an academic interference with students with special talents as Gallagher (1985) described it to be putting the student in an environment that challenges his abilities and meets the needs of his peers who parallel him mentally, not chronologically. It also makes the study period shorter than the one the student needs in the regular learning system.

Acceleration is one type of educational interference that started few centuries ago. Academic acceleration programs for the mentally distinguished students were found in some schools in the US before 19th century. The mentally distinguished students were allowed to finish the set curriculum in four years only instead of six needed for ordinary students. In 1868, this kind of interference was practiced in the schools of St. Louis, Missouri (Freeman, 1920). At that time, the schools used acceleration strategy to make sure that the talented students were able to finish the curricula faster without any cognitive gap (Gold, 1965).

This kind of practice was not confined to western countries only, but the majority of Gulf States witnessed a number of acceleration practices caused by the new learn system as many individuals of different ages.

Al-Jugheiman (2018) mentioned that he personally heard a number of narrators of that epoch that the condition by which the student was admitted to the suitable educational level was based on cognition test, irrespective of chronological age of the student. Despite that, acceleration was not founded on a scientific concept, but was randomly applied to all students heedful for the educational system, yet it was one of acceleration method regardless of causes.

The researcher considers acceleration to be the most practical method of the educational process. Many logical reasons were opted for choosing the acceleration system for the mentally gifted student because it allows him to develop in educational programs in ratio to his particular speed, thus meeting his special needs (Kulik \& Kulik, 1992). Due to that, acceleration might be considered an important education method that takes into consideration individual differences with regard to capabilities and cognition; this is what all concerned with developing education at the present time call for. With reference to what many educators in charge of sponsoring the gifted believe, academic acceleration moves towards having special programs that cater for the students with distinguished mental abilities that enable such students to develop more quicker at a younger age than what is offered in traditional education (Pressey, 1949). Academic acceleration is multifarious: partial acceleration which is presented to the student in a way that allows him to pass the scientific content horizontally; or total acceleration in which things are presented vertically.

Such diversity in acceleration programs offers different opportunities for mentally distinguished students to choose whatever makes him feel that it was designed to suit his excellence and propitiously meet his needs, abilities, and desires (George, 1997; Plucker \& Tylor, 1998; Hinds, 1981).

\subsection{Acceleration Policy in KSA}

KSA is distinguished for its interest in the gifted and excellent. Such an interest has been manifested in several ways among which are the following: enacting regulations and legislations concerned with the gifted and sponsoring them at the highest levels. As for adopting the policy of acceleration of the gifted students, this can be inferred from items in the register of student assessment (1419 A.H) approved by the higher committee of education policy. The explicatory memorandum - paragraph (3) - article (7) of that register stipulates that, due to the need to provide the gifted and the distinguished students with opportunities, head of the educational body or his deputy, within certain coordinated regulations, can decide to promote the student, who showed unusual excellence in his study, to a higher class.

In fact, the actual application of the acceleration system in KSA was procedurally performed in 1435 A.H. Time gap between establishing the policy and execution might be traced back to several reasons such as: the Saudi educational system being new, shortage of experienced educators, and the interest of higher bodies of education in establishing a suitable Saudi policy that stems from Saudi environment instead of adopting foreign policies for application.

The gifted acceleration policy in KSA depends on few regulations which can be classified into three basic 
constituents: study stage, acceleration procedures, and acceleration supervisory committees. The procedural index of applying the acceleration system 1438 - 1439 (A.H) (general management of the gifted, 1439) indicates that classes and study stages on which the acceleration system was applied were primary and intermediate stages. Thus, the student throughout his academic career in the general educational program was only given two chances of acceleration. The following table illustrates classes and acceleration stages.

Table 1. Classes and acceleration stages

\begin{tabular}{cc}
\hline Study Stage & Classes \\
\hline Primary & From: $4^{\text {th }}$ grade to sixth grade \\
Intermediate & From: $1^{\text {st }}$ intermediate class to third intermediate \\
\hline
\end{tabular}

As for implementation procedures, they are executed according to the following stages:

- Initial nomination

- Applying nomination regulations

- Approval of student's guardian

- Completion of acceleration records

- Approval of names

- Preparing and applying acceleration tests

- Acceleration approval and announcing results

As the education system in KSA is central, we find that the student's chance for nomination passes through numerous committees for approval and execution of acceleration program. Those committees constituted: members of the central committee for the acceleration system in the ministry of education, members of the acceleration committee in education department, and finally members of acceleration in the school.

\subsection{Acceleration Policy in the US}

Acceleration which is considered one the programs for sponsoring the gifted has recently drawn the attention of numerous American educators and expertise with regard to the significance of adopting a special relevant policy. Neihart (2007) suggested that education leaders should intensify research efforts related to academic acceleration when assessing its application at school level. With this in mind, acceleration policy has to be built in order to reflect the best practices based on most updated studies. In addition, the best use of the academic acceleration system makes it the most effective interference program that stimulates academic development of the excellent students (Kulik \& Kulik, 1992). The last report which was prepared in collaboration with the National Association of Gifted children (NAGC) and the National Society for Developing programs of the Gifted (NSDPG) revolves around the status of teaching the gifted in states of the U.S. The report presented various general data on discovering and sponsoring the gifted. In the data there were some linked with acceleration policy in the US. The foremost stated results in the aforementioned report stressed that following the federal policy of acceleration of the gifted might help students themselves, their families and mentors (American Educational Research Association, 1999). Although 13 states in 2015 adopted an acceleration policy, yet (12) of them left acceleration decision to the Local Educational Associations (LEA) without going back to the policy set for that, while other 15 states that didn't have an acceleration policy, yet left the door open for local education bureaus to accept or reject a policy of acceleration (Shappard, 2018).

American acceleration policy, despite diversity of execution which is sometimes not stipulated upon, yet it offered advanced methods in the field of acceleration, specifically at the university level. As Abu Naser and Al-Jugheiman (2012) mentioned, the reasons behind that might be attributed to: diversity of methods of field application, benefiting from past experiences, affluence of specialists in the field of education for the gifted, diversity of local and national organizations and their cooperation in the field of developing services offered to the gifted, richness of experimental researches, and expansion of authorship and publishing. Another opinion sees that it is necessary to adopt acceleration policy to retain rights of the gifted student and to ensure safe application based on scientific studies and experimental researches. 


\section{Research Procedures}

\subsection{Research methodology}

This research adopts the descriptive comparative method of the whole grade acceleration policy of the gifted students via an analytical comparative study between the policy of KSA and that of Massachusetts, USA. This policy is the one that best suits checking relations between variables and for unveiling differences among them, if any, in order to provide an analytical description of the phenomenon, subject of the study.

Choosing Massachusetts to specifically be the subject of the study was for the following reasons:

- The state ranks first in America in its educational system and academic level of its students, according to the latest American statistics (http://www.usnews.com/news/best-states/rankings).

- Students in public schools in Massachusetts ranked the highest in math and language all over America (Shore, 2000).

- The U.S attracts the best minds as it encompasses the strongest universities worldwide. Such as MIT, Harvard, and Yale.

\subsection{Study Sample}

It is a sample that randomly selected one from managements of the gifted in KSA, and from principals of schools for the gifted in Massachusetts, USA. The method of dividing the sample is illustrated in the following Table.

Table 2. Sample of the study

\begin{tabular}{ccccc}
\hline No. & Name & Country & Profession & Years of experience \\
\hline 1 & Kh.B & KSA (Ihsaa) & Supervisor of acceleration programs administration of the gifted & 3 years \\
2 & N.Gh. & KSA (Mecca) & Supervisor of acceleration programs administration of the gifted girls & 3 years \\
3 & M.E & Massachusetts, USA & Principal of Academy Hill School & 3 years \\
4 & N.G & Massachusetts, USA & Principal of Chestnut Accelerated School & 3 years \\
5 & J.S & Massachusetts, USA & Principal Brighton School & 3 years \\
\hline
\end{tabular}

\subsection{Research Instruments}

\subsubsection{Semi-Structured Interview}

The researcher adopted the interview method, being an instrument used to collect data in a descriptive manner. The dialogue was conducted using open-ended questions between the researcher and the concerned people. She followed the scientific method to verify validity and suitability. Questions of the interview were addressed to a number of specialists and expertise in the field of scientific research to verify and judge their quality and suitability. Based on questions of the research interview, the questions were divided into two subjects: first, nature of whole-grade acceleration policy:

This aims to verify whether there is a whole grade policy founded on scientific frameworks in KSA and the state of Massachusetts, USA.

Second subject: the mechanism of applying whole grade acceleration in the field of education.

This aims to compare the mechanism of whole grade acceleration in KSA with that in the state of Massachusetts, USA.

\subsubsection{Document Analysis}

the documents included reports of national organizations issued by the national association for gifted children (NAGC) such as the special report on sponsoring the gifted in the USA, data of practices and policies (2014 2015), in addition to the policy document on teaching the gifted approved by the State of Massachusetts and issued in 2002 by the administration concerned with education in the State. Equivalent to that, the document on teaching the gifted issued and approved by Ministry of Education in KSA (The gifted administration 1439 A.H), was used. It was the part relevant to index of gifted acceleration procedure (1438 - 1439 A.H).

The two documents of this research are classified into one category subdivided into two major subjects as illustrated below. The researcher adopted this method of classification in order to facilitate the comparison procedure and to unveil similarities and discrepancies between the two policies. Table 3 illustrates the mechanism of document analysis. 
Table 3. Mechanism of document analysis

\begin{tabular}{cc}
\hline \multicolumn{2}{c}{ Field: The policy of Whole Grade Acceleration } \\
\hline First theme & Second theme \\
\hline $\begin{array}{c}\text { Study stage (to determine study stages to which acceleration } \\
\text { system is applied) }\end{array}$ & $\begin{array}{c}\text { Acceleration procedures (these are the steps followed in applying whole } \\
\text { grade }- \text { acceleration system. }\end{array}$ \\
\hline
\end{tabular}

\section{Results}

The results provided answers to the research questions relevant to the application of the whole grade acceleration policy both in KSA and Massachusetts, USA through an inductive analytical comparison of the official documents and field practices in the two regions. The results were compared to the findings that modern scientific studies on the active whole grade policy came up with. Such results were discussed and explained through the perspective of theoretical literature and previous studies. The questions are as follows:

The major question: To what extent does a clear whole grade acceleration policy based on scientific frameworks exist both in Saudi Arabia and Massachusetts, USA?

Based on the analysis of official documents relevant to whole grade acceleration policy in KSA and Massachusetts, and based on the answers received from participants in the personal interview regarding the first question, three basic subjects were included in the general field known as whole grade acceleration policy covered the following three topics: First: study stages on which whole grade acceleration system was applied.

Second: procedures of whole grade acceleration policy. Third: inclusion of counseling services in the whole grade acceleration policy through presenting what follows.

Results, of the general field will be discussed in detail, First: every topic of the three subjects will also be discussed through an analytical comparison between the whole grade acceleration policy in KSA and its counterpart in Massachusetts, USA.

\subsection{Availability of Whole Grade Acceleration Policy}

\section{1) Acceleration Policy in KSA:}

Analysis results linked to procedural index issued by KSA ministry of education in 1438-1439 A.H, regarding acceleration of the students who demonstrated an unusual excellence, revealed that acceleration system, being one of the programs of sponsoring the gifted should be applied in accordance with a specific policy. Through examining and analyzing paragraph (4), item (4) of article thirteen stipulates that the ministry of education has the right to issue a decision to accelerate the student who show unusual excellence in a class higher than his (administration of the gifted, 1439 A.H, p:2). Thus, we find that the acceleration system which was applied since issuance of the document until now was the whole or class acceleration system. This is what (Kh.B) ascertained saying: "the acceleration system applied so far is the class type-in fact, the ministry exerted great efforts, established the acceleration policy and after detailed scientific studies in the field decided to apply it.

What can be elicited from these is that the chronological age of the programs sponsoring the gifted in KSA is short. Therefore, it can be said that adopting a clear definite policy of whole grade acceleration and applying it in accordance with scientific studies is considered a reinforcing factor to develop the future perception of sponsoring the gifted in KSA. In addition, having a definite policy supervised by competent committees represented in higher and local supervisory bodies referred to in the document might decrease the possibility of individual prejudice. This opinion is reinforced by what a number of studies mentioned that in the absence of policy, some authorities might utilize it in an unprofessional manner in which personal prejudices might interfere (Scott et al., 2017, p. 122).

2) Acceleration Policy in the State of Massachusetts:

Result analysis of the document of Massachusetts education policy, the part entitled "motivating students with high performance: policies and academic programs offered to the distinguished students mainly in the part on acceleration policy adopted by the state, indicate that the acceleration policy practiced by public schools in the state is a content acceleration one (Massachusetts Department of Education, 2020). The whole grade acceleration was never mentioned in the document. As a result, it was never mentioned in the document. Thus, the whole acceleration was not officially found in the services offered to the gifted in the state.

The report issued by the national association for the gifted (Bade, 2015) based on the survey conducted to unveil the states that do not adopt a particular acceleration policy, emphasizes that Massachusetts was one of the states 
that didn't have one. More than that, the researcher was able to obtain more information from other sources, one member of Massachusetts Association for Gifted Education (MAGE) which disclosed that the acceleration policy didn't exist. The belated adoption of the state of a policy for the gifted was because no significant educational efforts were exerted to serve them (J.S) stated: "The reason behind that was the education bureau believed that the level of education was high so there was no need for gifted programs. Unlike other poor states such as Carolina whose education level was low, Massachusetts intensified efforts in sponsoring the gifted, a human power, which will raise up society in the future."

Such a belief is misleading because education that copes with the student's abilities and needs is a right. This is what modern educational trends emphasized, and reiterated by Scott et al. $(2017$, p. 121) who declared that the rejection of some states to adopt an acceleration policy was wrongly understood. With regard to the federal educational system in the US, policy and legislations pertaining the gifted in the state do not accept acceleration systems applied in private schools. Thus, we find that a number of private schools take acceleration decision according to the academic achievement the students show. Quite often, the policy is applied in accordance with the evaluation of, teacher, guardians, and school principals. Such results agree with those of (Van Tassel-Baska, 2018) study in which he emphasized that the defect in developing sponsoring the gifted in the U.S as expected was due to the absence of a unified gifted education policy at the country level. An example of that is Academy Hill School which applies the acceleration system in accordance with classes and content. (M.E) the principal of that school assured stated "we don't have an acceleration policy because we deal with the gifted students case by case; we apply the acceleration system according to the needs and special capabilities of the gifted students. As a result, school policy rejects to place the gifted student in a specific mould from which if he deviates is banned.

From a general perspective, this opinion might be regarded positive, but at the same time it might prevent the gifted category of students from this opportunity due to social and psychological nature of the students or to prejudice of the teacher. This opinion agrees with the recommendations of the New York Comprehensive Center (2012) which states that the school that applies the acceleration system must have a written policy which includes clear procedures for applying the system (as a whole or early admission to kindergarten or to college). This policy should be open to teachers and guardians for cognizance and to be followed as a guideline for student selection and for evaluating his achievement.

First question: what is the range of applying whole grade acceleration system to all stages of study?

Subject (1): study stages to which whole grade acceleration system is applied:

KSA: the document of whole grade acceleration policy (the gifted administration, 1439 A.H:4) reveals that the acceleration system is applied to primary and intermediate stages, determining classes for acceleration which are: promotions from fourth grade to sixth and from first to third intermediate. It is noted that no indication in the document was given to justify and tell why specifically those classes were selected by the ministry for acceleration. However, Scott et al. (2017) support such selection; they see that it is better to promote the student to the year prior to the final one of the stage because the student's promotion to a transitional period might hinder adaptability (p: 124). It is logical that promoting the student in the same stage of education or within the school environment familiar to him will create a positive role in adaptability. Contrary to that is moving to a new school environment and to a different stage of education that will make psychological and social adaptability more difficult and will consequently affect the student's academic development. (B.Kh.) provides details on the time of applying acceleration system at these stages saying: "the system started in 1437 extending till 1440, but in the past the system was also applied at the secondary stage as well, but was stopped in the last stage.

Any analytical reading for what is between lines reveals that the supervisor wants to draw attention to the issue of preventing the secondary stage from acceleration program. When one considers that the secondary stage in KSA education system depends on cumulative average system for university acceptance, then that might explain why he is banned. Researchers at the same time might find that this decision contradicts with the objective for which the acceleration policy in KSA was designed. In general, obliging the gifted student to get the chance of acceleration at certain definite stages of his study makes the policy sound rigid.

This result agrees with the study of Abu Naser and Al-Jugheiman (2012) which emphasized that the gifted acceleration policy in KSA should be redesigned in light of the special needs of the gifted. This process contradicts with what scientific researchers came up to regarding the best ways of applying whole grade acceleration characterized by being available, just, and flexible (Lupkowski-Shoplik, Behrens, \& Assouline 2018).

3) The state of Massachusetts: 
Though the state doesn't have any specific policy to apply whole grade acceleration as stated before, yet the document includes an acceleration policy as mentioned in the document, known as compressed curriculum. The document indicated that the stage in which acceleration policy might be applied is from grade six to eight. It also explains why classes from kindergarten till fifth grade were excluded from applying the acceleration system because the intermediate level provides a variety of courses and electives with different academic levels. Such a thing provides the student with a chance to progress in accordance with his abilities. As for the primary stage, the focus is on building basics of English and math Syllabi (Massachusetts Department of Education, 2020).

Findings of personal interviews assure that the special policy of the school applies to all stages. (M.E.), the principle of the academy mentions that: "the whole grade acceleration system will be applied to all classes and stages once the students show unusual excellence and obtain academic distinction.

For example, we have a number of students who were promoted from fourth grade to sixth and others from first to third "a transition". Such an answer clearly shows to what extent the adopted acceleration policy is flexible in this school; it secures chances to all students, irrespective of age to move to a level higher than their chronological age. This meets the aims of the gifted in achieving democratic type of education which offers same opportunities to students to gain knowledge, develop their abilities, and meet their needs. If the students are bound to certain definite shackles related to curricula and stages of learning, this nullifies democracy (Amer, 2009, p. 180).

Second question: To what extent do applying whole grade acceleration procedures meet educational objectives of sponsoring the gifted?

Subject (2): Whole Grade Acceleration Procedures:

KSA: the results of analyzing the part relevant to acceleration procedure in the document reveal that the central committee of acceleration in the ministry of education has exerted a great effort in selecting the gifted student very precisely and objectively. The proof of that are the details the document includes with regard to applying the acceleration system at eight stages. Each stage has its procedures, bodies responsible for implementation, and time period for execution. The most important stages which should be focused on are nomination and verification of nomination control. The concern of designers of whole grade acceleration policy to determine the highest percentage in measuring the talent with a percentage higher than $2 \%$, equivalent to (705) out of (880) was the outcome of academic studies concerned with intelligence tests. Gallagher (1985) suggested that the student whose average was 130 or higher in IQ test is academically propitious to join the whole acceleration program; while other studies assured that 135 is the suitable score for the who grade acceleration decision (Davis \& Rimm, 1989; Terman \& Oden, 1947).

The next step is verification of academic achievement. The nominee must score not less than $98 \%$ for the intermediate level and excellent for the primary one. Results of personal interview ascertain that adopting such a strategy in nomination for the acceleration system is quite exact. (N.kh.) says: "In fact, the elite of the students are chosen. For example, 500, 600, or 700 students in Jeddah area compete, but the number of nominees is very few 2,3, or even one sometimes is chosen.

Such evidences indicate that the whole grade policy was meticulously based on modern education directives. This policy agrees with the recommendations of modern studies that the actual gifted students, who deserve the best interference acceleration system which suits their abilities are those, whose scores are within the range of $99.9 \%$, but such students are very rare, one out of 10,000. That dictates a special educational interference (Lupkowski-Scholik, Behrens, \& Assouline, 2018). Determining responsible authorities for applying and correcting standards should be through competent committees in the field of gifted sponsorship. These are (Central committee for acceleration in the general administration of the gifted and acceleration committee in the directorate of gifted education) as such a thing increases validity of results. (Kh.B) states assuringly: "After applying the regulations, administration of the gifted sends the list of names to the ministry of education. At this stage the names are verified by the acceleration committee in the ministry which, in turn verifies the names as some area administrations had already erred in nomination."

In the researcher's opinion, it is a precautionary measure taken by a higher competent administration because applying the acceleration system is still in its beginnings. Therefore, it is necessary to secure the correct performance of administrations of the gifted all-over different areas. Moreover, acceleration decision requires a high degree of exactness in nomination and selection. The procedure of creating an awareness plan prior to the approval of the student's guardian is considered by the researcher one of the modern educational practices through which persons concerned with acceleration system application (guardians, teachers, or targeted) should be provided with an integrated picture of acceleration, its characteristics, and stages. These steps are followed by 
a personal interview as determined in the document with a passing score (70). All acceleration program supervisors agree that it is an essential step for it reveals the student's readiness and enthusiasm to enter the acceleration system as described by (N.Gh.): "personal interview reveals a number of psychological and social qualities which are hard to discover through paper exams... the interview questions aim to check the student's intelligence and smartness in addition to flexibility of thinking, self-confidence, motivation, emotional equilibrium, and writing skills."

Modern literatures state that adopting the acceleration decision for the gifted student should not only rely on exam criterion, but should also depend on the comprehensive criterion assessment to include: observation and interview, in addition to informal procedures like reviewing academic record (Wood, Portman, Cigrand, \& Colangelo, 2010).

At the last step of acceleration approval, the targeted students are subjected to the acceleration test which examines the major skills of the courses of the class to which they will be accelerated. The passing grade is $75 \%$ determined as the general rate equivalent to $50 \%$ for each course. To unveil the reason behind determining such percentages, the study of Wood, Portman, Cigrand, \& Colangelo (2010) assured that the ideal method to determine readiness of the student for acceleration is the level of his performance in the Aptitude Test. Performance is labeled above general average of the accelerated class if the student scores $50 \%$ in each course (this implies that he is ready for more challenging courses), and $75 \%$ as a general average in the test accordingly. The student is here described to have an exceptional ability. Moreover (Kh.B.) comments on the acceleration test: "The numbers of students who pass this test are very few because such a test is very accurate and measures students' higher mental skills".

This result sounds logical to a great extent for the procedures sound to be based on a number of accurate experiments and on studies of national and international nature. Despite the accurate measures taken in selecting students who deserve whole grade acceleration system, yet there are still some issues that need contemplation and reconsideration, the foremost of which are: excluding the teacher from taking part in the decision of student's acceleration, though he is a basic element, being the closest and the most capable to determine the one who deserves it most. The mechanism of test preparation places high pressure on the student and his guardians since it is given at the beginning of summer vacation which implies that the student has to prepare for it throughout school year. This study agrees with that of (Al Qadi, 2015).

4) The State of Massachusetts:

Schools applying acceleration system in the state lack official documents that explain stages and procedures of applying whole grade acceleration. As stated before, the samples participating in the research disclosed the steps followed in applying acceleration in their schools through a personal interview designed through individual discretion. For example, (M.E) explains acceleration procedures in her school as follows: "the initial nomination stage includes: teacher's nomination and administering a comprehensive exam, called Achievement Test, for all students to secure getting the best scores.

Test analysis is based on accuracy of student's answers compared with time period needed for answering the questions, comparing the results with the general level of his peers. The next step is to verify excellence of the students through giving them another test, Ability Assessment Test. When such students pass the specified skills, then a decision for their acceleration is taken. The student afterwards is promoted to a higher-class, pending approval of the student and his guardian. (Translated)

What is elicited from this case indicates that the mechanism adopted in applying the whole grade acceleration system, although it wasn't designed in light of academic studies but applied in accordance with discretion of school administration, yet it reflects an awareness of the administration of the basics according to which distinguished students are selected. It also shows a strong belief in the significance of acceleration from this category in order to provide those who deserve acceleration with a chance by which they can achieve the major educational objective set by the school. The objective is the individual's right to learn in accordance with his abilities and needs, but at the same time absence of an official acceleration policy may lead to irregular individual practices which dissuade active applying of the acceleration System (Van Tassel-Baska, 2018).

Third Question: To What Extent Do Guidance Services Relevant to Whole Grade Acceleration System Avail?

Third Subject: Including Politics in Guidance Services.

KSA: the document included guidance services as one of the stages of applying acceleration system. Such services were implemented at two stages (awareness and adaptability). Through examining and pondering over the nature of the adopted procedures in the two guidance services in the whole grade acceleration policy, it might 
be classified under two types (precautionary guidance/ awareness and remedial guidance/ adaptability). The awareness stage briefs the student and family on acceleration, benefits, and consequential controls. (Kh.B) described the nature of the application stage saying "Before students set for the acceleration exam, the gifted department in collaboration with school provides an awareness program on acceleration and its benefits either through meetings with guardians and candidate students or through sending text messages."

We can deduce from this answer that awareness program is offered for the students targeted for whole grade acceleration and for their guardians in several ways which reflects how gifted administrations in the kingdom of Saudi Arabia are aware of the significance of this step. The researcher can't assure that the awareness stage has been definitely implemented in all administrations of the gifted because the acceleration policy lacks items on the executive procedure of the awareness guidance program prior to acceleration implementation. This result copes with that of Sheppard (2018) and with Abu Naser and Al-Jugheiman (2012) as well. As for the adaptability stage, it particularly measures the psychological and social aspects of the student and his ability to integrate with the accelerated class.

In this respect, (N. Gh.) adds: "The school sends a form to be filled out by the advisor on the student's adaptability to make sure that the student adapts himself socially and psychologically to the higher class for which he was promoted. The form also sheds light on his progress and whether the services were preventive or remedial. This persists for almost forty days. Afterwards, the form is sent to the central committee in education directorate to decide whether the student is adapted to go ahead with acceleration, if not, he returns to his normal class.

Determining the experimental period of the student's adaptability to the whole-grade acceleration program needs 30 days according to what is stated in the document and reinforced by the results of the interview. This copes with the recommendations of the report on developing academic acceleration policy; an adequate period to monitor the student's aspects: psychological, social, and cognitive, as some students show low self-confidence or stress at the beginning of the acceleration process. This issue sounds normal when considering the new experiences to which the accelerated student is exposed (Shoplik, Behrens, \& Assouline, 2018). What can be elicited from the guidance services included in the steps of accelerating the gifted students is the decision makers' awareness of the significance of guidance programs and of considering it to be an essential part of student's acceptance to the acceleration system.

5) Massachusetts State:

(M.E), the principal of Hell Academy, assures that guidance services offered by the school to accelerated students are confined to observation period which lasts for 30 or 40 days. During that period focus will be on student's academic interaction and psychological and social adaptabilities. Once the student shows adaptability, acceleration system persists. (Translated)

Commenting on the outcome of this response, one can conclude that the guidance service the school focuses on regarding applying the whole grade acceleration system is a remedial guidance program which verifies student's adaptability. As for the guidance services that precede the acceleration process which is often presented in the form of awareness preventive programs, they don't offer anything to the acceleration nominees or to their guardians. What attracts attention, regarding guidance services applied in schools in general, is that they still need development especially in the awareness or preventive field (prior to applying acceleration). Such an opinion agrees with the results of Sheppard's (2018) study which indicated that preventive guidance services were inadequate in the American schools participating in the study sample whether those schools adopted an acceleration policy or not. $53 \%$ of the answers of that sample didn't encourage taking the whole-grade acceleration decision.

In summary, one notices that there is a big difference between KSA and the state of Massachusetts with regard to the availability of a real definite whole-grade acceleration based on scientific frameworks. at first, in KSA the researcher found that there exists a special policy relevant to whole grade acceleration, a documented policy written by a committee of specialists in the field of gifted sponsorship, while private schools applying the whole grade acceleration system in the state of Massachusetts lack a clear written policy. Henceforth, they apply acceleration in light of directives and prudence of certain individuals.

\section{Recommendations}

In light of the previous results, the researcher recommends the following:

- There is a need to deepen school and community awareness on positive effects of acceleration.

- The need to create student guidance directory and distribute it to all schools that apply academic 
acceleration systems with a clear executive vision determined for advisors explaining the role of everyone working in the field of gifted sponsorship.

- The need to involve individuals working in schools (such as distinguished teachers, academic and psychological advisors) in creating acceleration policy.

- Because orientation and guidance are two significant pillars in the whole-grade acceleration program in specific, the study recommends to prepare academic professional staff specialized in gifted students' guidance.

- To develop a strategic vision for the current acceleration policy to include two elements: openness and flexibility through which acceleration circle could be widened to encompass all stages of education.

- To create a course acceleration system for the secondary stage to be an alternative for the whole grade acceleration of this stage so as not to prevent genius students from joining universities and graduate at a younger age.

\section{References}

Abu Naser, F., \& Al-Jugheiman, A. (2012). Administration and educational policies in the field of the gifted and the creative. Amman, Jordan: Dar Al-Maseerah.

Al-Baalabaki, M. (2003). Al-Mawrid. Lebanon: Dar Al-Ilm Lilmalayeen.

Al-Jugheiman, A. M. (2018). Comprehensive directory in designing and implementing educational program for the gifted. Al-Obeikan: Riyadh, KSA. Directory of procedures for student acceleration who showed unusual excellence in stages of general education. General Administration of the gifted, 89760:28, KSA.

Al-Jugheiman, A., Abu Naser, F., Maajeni, O., Abu Aouf, T., Ayoub, A., Banajah, S., \& Abdel Karim, I. (2009). Evaluation of the talented care program in general education schools in the Kingdom of Saudi Arabia. Unpublished study deposited by the Ministry of Education in the Kingdom of Saudi Arabia, Riyadh.

Al-Qadi, M. S. (2015). A proposed vision for applying academic acceleration system in Saudi education in light of experiences of other countries (Unpublished dissertation). Faculty of Education: Umm Al-Qura University.

Amer, T. A. R. (2009). Modern trends in discovering the gifted and excellent: Qualities and sponsorship. Cairo, Egypt: Academic library.

American Educational Research Association. (1999). American Psychological Association National Council on Measurement in Education. Standards for educational and psychological testing. Washington, DC: American Educational Research Association.

Bade, J. M. (2015, May). 2e and IDEA: The right to assessment and services. 2e Newsletter. Retrieved from http://www.2enewsletter.com/subscribers_only/arch_2015_5_2e\%20and\%20IDEA_JMB.html

Davis, G. A., \& Rimm, S. B. (1989). Education of the gifted and talented. Prentice-Hall, Inc.

Freeman, F. N. (1920). Provision in the elementary school for superior children. The Elementary School Journal, 21(2), 117-131. https://doi.org/10.1086/454892

Gallagher, J. J. (1985). Teaching the gifted child (3rd ed.). Boston: Allyn \& Bacon.

Galton, F. (1869). Hereditary genius. London: Macmillan. https://doi.org/10.1037/13474-000

George, D. (1997). The challenge of the able child (2nd ed.). London, David Fulton Press.

Gold, M. J. (1965). Education of the intellectually gifted. Columbus, OH: Charles E. Merrill Books, Inc.

Hinds, G. J. (1981). Adolescents gifted in the performing arts: Study of self-reports.

Jarwan, F. (2012). Methods for discovering and sponsoring the gifted (3rd ed.). Amman: Dar Al-Fiker.

Kulik, J. A., \& Kulik, C. L. C. (1992). Meta-analytic findings on grouping programs. Gifted Child Quarterly, 36(2), 73-77. https://doi.org/10.1177/001698629203600204

Lupkowski-Scholik, A., Behrens, W. A., \& Assouline, S. G. (2018). Developing academic acceleration policies: whole grade, early entrance \& single subject. Retrieved from http://www.accelerationinstitute.org/ Resources/Policy_Guidelines/Developing-Academic-Acceleration-Policies.pdf

Massachusetts Department of Education. (2020). Retrieved from http://www.doe.mass.edu/

Neihart, M. (2007). The socioaffective impact of acceleration and ability grouping: Recommendations for best 
practice. Gifted Child Quarterly, 51(4), 330-341. https://doi.org/10.1177/0016986207306319

New York Comprehensive Center. (2012). Academic Acceleration: Summary of Research and Policy Considerations Informational Brief. Retrieved from http://www.k12accountability.org/resources/GiftedEducation/grade-accel-brief-revised-Nov-2012.pdf

Plucker, J. A., \& Taylor, V, J. W. (1998). Too much too soon: Non-radical advanced grade placement and the self-concept of gifted students. Gifted Education International, 13(2), 121-135. https://doi.org/10.1177/026142949801300205

Pressey, S. L. (1949). Educational acceleration: Appraisal and basic problems. Bureau of Education Research Monographs, No. 31. Columbus, Oh: The Ohio State University Press.

Rogers, K. B. (2005). The academic effects of acceleration. In N. Colangelo, S. G. Assouline, \& M. U. M. Gross (Eds.), A nation deceived: How schools hold back America's brightest students (pp. 47-58). Iowa City, IA: Belin/Blank International Center for Gifted Education and Talent Development.

Scott, J., Michael, S., Matthew, T., \& McCoach, D. B. (2017). Beyond education of the gifted: discovery, qualities, and sponsorship. Prufrock Press Inc, Waco, Texas. Dawood Qarni (trans.), Riyadh: Obeikan for publishing and distribution.

Sheppard, A. A. (2018). Knowledge, perceptions, and beliefs of elementary principals regarding whole-grade acceleration for gifted students. The College of William and Mary.

Shore, B. M. (2000). Metacognition and flexibility: Qualitative differences in how gifted children think. In R. C. Friedman, \& B. M. Shore (Eds.), Talents unfolding: Cognition and development (pp. 167-187). Washington, DC: American Psychological.

Terman, L. M., \& Oden, M. H. (1947). Genetic studies of genius: The gifted child grows up. Stanford, CA: Stanford University Press.

Van Tassel-Baska, J. (2018). American policy in gifted education. Gifted Child Today, 41(2), 98-103. https://doi.org/10.1177/1076217517753020

Wood, S., Portman, T. A. A., Cigrand, D. L., \& Colangelo, N. (2010). School counselors' perceptions and experience with acceleration as a program option for gifted and talented students. Gifted Child Quarterly, 54(3), 168-178. https://doi.org/10.1177/0016986210367940

\section{Copyrights}

Copyright for this article is retained by the author(s), with first publication rights granted to the journal.

This is an open-access article distributed under the terms and conditions of the Creative Commons Attribution license (http://creativecommons.org/licenses/by/4.0/). 